\title{
Scarplet: A Python package for topographic template matching and diffusion dating
}

\author{
Robert Sare $^{1}$ and George E. Hilley ${ }^{1}$ \\ 1 Department of Geological Sciences, Stanford University
}

DOI: $10.21105 /$ joss. 01066

\section{Software}

- Review ¿

- Repository u

- Archive ${ }^{\top}$

Submitted: 16 October 2018

Published: 27 November 2018

\section{License}

Authors of papers retain copyright and release the work under a Creative Commons Attribution 4.0 International License (CC-BY).

\section{Summary}

Detection and analysis of landforms is a major problem in geoscience, including identifying and measuring the relative ages of earthquake fault scarps. Inverse methods using the diffusion equation have been applied to relatively date a wide range of landforms, including scarps (Hanks, 2000; Hilley, DeLong, Prentice, Blisniuk, \& Arrowsmith, 2010), terraces (Avouac \& Peltzer, 1993), and impact craters (Fassett \& Thomson, 2014). Size (height) and relative age estimates from these techniques provide important constraints where instrumental or historic data may be sparse: for example, in a fault zone with a limited record of historic seismicity. Similar wavelet-based methods are widely used in geophysics and channel network analysis as feature extraction techniques (Lashermes, Foufoula-Georgiou, \& Dietrich, 2007; Passalacqua, Tarolli, \& Foufoula-Georgiou, 2010).

The scarplet package provides a set of tools for performing feature detection and diffusion dating using user-defined landform templates. The package contains several template functions implemented for vertical scarp dating as well as a crater template and common functions such as the Ricker wavelet. As the template matching approach can exploit simple map-reduce parallelism, it can be efficiently applied to large datasets in a distributed manner.

The core algorithms of scarplet use standard signal processing tools in the scientific Python ecosystem, and the WindowedTemplate base classes used by these methods are easy to extend. The intent is to provide a quick, scalable option for topographic data analysis and template function prototyping which can be adapted by users familiar with NumPy and SciPy. As availability of digital topographic data from airborne and satellite sources grows, tools like this will help to enable quantitative geomorphology on regional and global scales and complement Python-based modelling packages such as LandLab (Hobley et al., 2017).

\section{Acknowledgements}

We would like to thank edtor Kristen Thyng, Fiona Clubb and Eric Hutton for constructive reviews of this package, and Sam Johnstone and Stephen DeLong for helpful discussions of scarp dating. Development was supported by a grant from the National Earthquake Hazards Reduction Program (award number G17AP00010). Example data was accessed using data services provided by the OpenTopography facility with support from the National Science Foundation under NSF award numbers 1557484, 1557319, and 1557330 . 


\section{References}

Avouac, J.-P., \& Peltzer, G. (1993). Active tectonics in southern Xinjiang, China: Analysis of terrace riser and normal fault scarp degradation along the Hotan-Qira fault system. Journal of Geophysical Research: Solid Earth, 98(B12), 21773-21807. doi:10.1029/93JB02172

Fassett, C. I., \& Thomson, B. J. (2014). Crater degradation on the lunar maria: Topographic diffusion and the rate of erosion on the Moon. Journal of Geophysical Research: Planets, 119(10), 2255-2271. doi:10.1002/2014JE004698

Hanks, T. C. (2000). The age of scarplike landforms from diffusion-equation analysis. Quaternary Geochronology, 4, 313-338. doi:10.1029/RF004p0313

Hilley, G. E., DeLong, S., Prentice, C., Blisniuk, K., \& Arrowsmith, J. R. (2010). Morphologic dating of fault scarps using airborne laser swath mapping (ALSM) data. Geophysical Research Letters, 37(4), L04301. doi:10.1029/2009GL042044

Hobley, D. E. J., Adams, J. M., Nudurupati, S. S., Hutton, E. W. H., Gasparini, N. M., Istanbulluoglu, E., \& Tucker, G. E. (2017). Creative computing with Landlab: an opensource toolkit for building, coupling, and exploring two-dimensional numerical models of Earth-surface dynamics. Earth Surface Dynamics, 5(1), 21. doi:10.5194/esurf-5-21-2017

Lashermes, B., Foufoula-Georgiou, E., \& Dietrich, W. E. (2007). Channel network extraction from high resolution topography using wavelets. Geophysical Research Letters, 34(23), L23S04. doi:10.1029/2007GL031140

Passalacqua, P., Tarolli, P., \& Foufoula-Georgiou, E. (2010). Testing space-scale methodologies for automatic geomorphic feature extraction from lidar in a complex mountainous landscape. Water Resources Research, 46(11), W11535. doi:10.1029/2009WR008812 